\title{
Integrating Spatially Explicit Representations of Landscape Perceptions into Land Change Research
}

\author{
Monica A. Dorning ${ }^{1}$ - Derek B. Van Berkel ${ }^{2}$ - Darius J. Semmens ${ }^{1}$
}

Published online: 8 August 2017

(C) US Government (outside the USA) 2017

\begin{abstract}
Purpose of Review Human perceptions of the landscape can influence land-use and land-management decisions. Recognizing the diversity of landscape perceptions across space and time is essential to understanding land change processes and emergent landscape patterns. We summarize the role of landscape perceptions in the land change process, demonstrate advances in quantifying and mapping landscape perceptions, and describe how these spatially explicit techniques have and may benefit land change research.

Recent Findings Mapping landscape perceptions is becoming increasingly common, particularly in research focused on quantifying ecosystem services provision. Spatial representations of landscape perceptions, often measured in terms of landscape values and functions, provide an avenue for matching social and environmental data in land change studies. Integrating these data can provide new insights into land change processes, contribute to landscape planning strategies, and guide the design and implementation of land change models.

Summary Challenges remain in creating spatial representations of human perceptions. Maps must be accompanied by descriptions of whose perceptions are being represented and
\end{abstract}

This article is part of the Topical Collection on Effects of Landscape Structure on Human Wellbeing

Monica A. Dorning

mdorning@usgs.gov

1 Geosciences and Environmental Change Science Center, U.S. Geological Survey, DFC, MS980, PO Box 25046, Denver, CO 80225, USA

2 Center for Geospatial Analytics, North Carolina State University, Raleigh, NC, USA the validity and uncertainty of those representations across space. With these considerations, rapid advancements in mapping landscape perceptions hold great promise for improving representation of human dimensions in landscape ecology and land change research.

Keywords Land change process - Land management . Landscape perception $\cdot$ Landscape change $\cdot$ Landscape values $\cdot$ Spatial

\section{Introduction}

People perceive landscapes differently. The landscape could be seen as a wealth of opportunity, such as the site of a new development or a productive field for growing food. Alternatively, it could be a site for recreation and relaxation, a place to call home, or an area of potential danger. Such perceptions are the first link in a chain of cognitive processes that contribute to decision making [1•]. Subsequent interpretations and evaluations of landscapes lead to the formation of values (desirability of different outcomes) and preferences (actual desires), shaping how an individual or group responds to and manages or uses the landscape $[1 \bullet, 2]$. Recognizing the diversity of people's landscape perceptions across space and time is essential to understanding this process and resulting heterogeneity in emergent landscape patterns.

Recognition of perceptual human drivers of landscape change has resulted in greater interest in methods for systematic characterization of different landscape values and preferences. Scientists from the land change community have steadily borrowed techniques and methods from landscape perception research for perception evaluation [e.g., 3-5] and vice versa [e.g., 6, 7]. Despite numerous examples of including human perceptions in land change science, the challenges 
of developing accurate spatial representations of perceptions that reflect dynamics over time has meant that full integration of these human drivers has remained somewhat elusive $[8,9]$. For example, land change analysis is often based on evaluation of environmental factors alone due to few long-term surveys of perceptual values, omitting the human-environment interactions that contribute to land use decisions [e.g., 10, 11]. While considerable advances have been made in integrating decision-making in models of land change [12], model assumptions are often not reflective of the complex perceptual value-to-decision chain. Lack of multi-temporal, spatially explicit data has resulted in numerous models that, while approximating social processes (e.g., GDP, education level, or distance to market), crudely represent how these characteristics shape perceptions. Moreover, such proxies do not represent heterogeneity in values across and within social groups. Though there have been continuing calls for integrating human dimensions in landscape ecology and land change research over the last 30 years $[13,14,15 \cdot, 16-18]$, there remains a need to integrate spatially explicit social science data with biophysical landscape measurements for improving explanation of land change processes and patterns $[16,19]$.

Fortunately, methodologies are emerging that create new opportunities for integrating spatially explicit information about human perceptions into studies of landscape change. Observation and study of landscape change have advanced rapidly in the era of remote sensing and big data [20]. Immersive technologies, participatory mapping, social media, and other novel spatially referenced social data present promising avenues for improving spatial representation of landscape perceptions. We present an overview of these new and emerging methods and their applications in land change studies to demonstrate how such techniques can be leveraged in land change research. In this review, we (1) provide an overview of the role of landscape perceptions in the land change process, (2) demonstrate advances in quantifying and mapping landscape perceptions, (3) describe how these emerging analytical techniques have and may benefit land change studies, and (4) discuss challenges and opportunities associated with integrating spatially explicit human perceptions in land change research.

\section{Overview of Landscape Perceptions and the Land Change Process}

Anthropogenic land change processes involve a number of factors that operate at multiple institutional, spatial, and temporal scales [16]. In very simple terms, a desired change is acted upon by an individual or group, causing a corresponding change in the landscape [21]. Fully understanding this process requires evaluation of the human decision-making components that lead to the chosen action. In selecting an appropriate management action, individuals or groups perceive the landscape and its characteristics, the internal and external driving forces underlying the need or desire for change, and any additional social and environmental characteristics constraining their choices (Fig. 1) [1・, 13, 21, 22]. The decision-making process involves interpreting and evaluating these factors and the tradeoffs associated with potential actions and is further shaped by individual experiences within societal context. The process culminates in the selection of an action that affects the landscape, in turn influencing future perceptions, driving forces, and constraints. All together, these factors determine the quantity, location, and pattern of landscape change.

Perceptions act as a lens through which people interpret landscapes using all of their senses. It is well established that this lens is also affected by contextual factors, including those related to cultural and individual experiences (e.g., knowledge, landscape context, socioeconomic factors, or social norms) $[13,14,23,24]$ and images and attitudes that form an individual's worldview. Worldviews have been investigated in multiple studies $[25,26]$ that aim to differentiate individual views of nature and how this translates into perceptions of, interactions with, and activities in landscapes. While not mutually exclusive, an individual's views of landscape can be classed into three categories of human-nature interaction: (1) wild/ wilderness, where human influence is, or should be, absent;

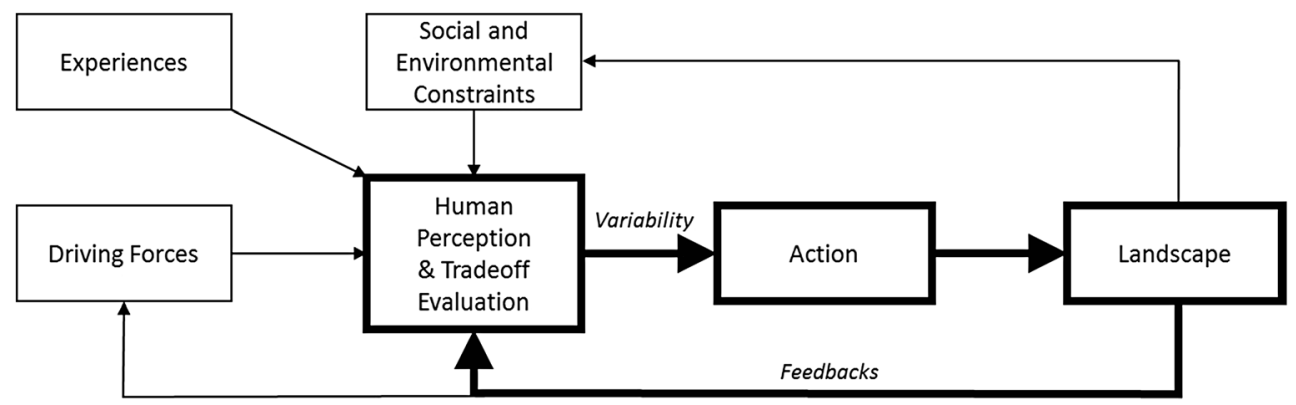

Fig. 1 The process of anthropogenic landscape change involves human perception and evaluation of (1) the landscape, (2) other social and environmental constraints, and (3) driving forces. This leads to an assessment of tradeoffs associated with alternative responses and the selection of an action that affects the landscape. Social and individual experiences also shape the decision-making process. This review is focused on the human-landscape interaction process (emphasized), including variability and feedbacks in the system 
(2) a functional view where the landscape is seen in utilitarian terms for leisure or extractive use; (3) or an Arcadian view where landscapes are a harmonious interaction between humans and nature [26]. This creates variability in how individuals perceive landscapes, leading to different interpretations and evaluations. However, it is not uncommon for communities to have a sense of shared landscape values, particularly within similar stakeholder groups [27]. Values associated with the landscape can be positive (e.g., esthetic or functional values) or negative (e.g., environmental hazards or unfavorable change). Perceptions are also dynamic; they change as landscapes and individuals change over time $[6,26]$. Challenges exist when perceptions do not align with environmental realities (e.g., changes to the landscape that are esthetically pleasing, but result in loss of biodiversity), requiring explicit consideration that is separate from, though related to, biophysical features [28].

Responses to perceived landscape characteristics can drive management decisions on private and public land [29]. While humans perceive and intentionally alter landscapes at a very particular "human" scale [14, 22], management decisions can occur at multiple spatial, temporal, and organizational scales, and may also affect land-use intensity. This could range from individuals making small changes in management on their own properties to the planning of cities and parks in accordance with planner or stakeholder perceptions (e.g., [30, 31]). Variability in human perceptions contributes to variability in the locations and patterns of landscape change. The "sense of place" and future horizons of individuals and communities influence this geographic and temporal scope. Human perceptions of and subsequent actions in response to changes in landscape structure also generate feedbacks in the humanenvironment interaction process $[15 \bullet]$.

\section{Advances in Quantifying Landscape Perceptions}

Landscape perceptions have been conceptualized as part of the human-environment interaction and decision-making process dating back to the late 1960s. These concepts originated with the cultural turn in geography and the recognition that space and especially place are socially constructed [32], as well as an increased interest in the management of scenic resources [2]. This led to the emergence of an entire field of study focused on landscape perception, including landscape assessments, preferences, and esthetics [2] and work on how these perceptions translate into decision making about the landscape [33]. Research focused on environmental cognition has tangentially investigated perceptions as well, investigating how individuals structure their thoughts regarding environmental issues, how this is learned, and how cognition influences behaviors [34]. A number of studies discuss the history and theory of landscape perceptions, with particular emphasis on landscape esthetics, landscape quality assessment, and environmental cognition $[1 \cdot 13,14,22]$. We refer readers to these studies for an in-depth overview of these research areas.

Significant advances have been made in capturing landscape perceptions in a growing number of studies ${ }^{1}$ $(n=587)$. Landscape, planning, environmental management, and tourism fields (Fig. 2) have recognized the importance of how perceived and real changes alter the way land and landscape are used. Within this literature, a major thrust has been to quantify and measure perceived values or preferences [35]. Surveys that evaluate preference using landscape photographs have been particularly pronounced $(n=178)$, especially in the field of landscape esthetics, while non-visual and in situ surveys that capture landscape impression have likewise been widely used $(n=151)$. More recent sources of information such as photorealistic images $(n=24)$ and virtual or immersive environments $(n=9)$ have leveraged new capabilities for manipulating images, allowing comparisons and increased realism. While these techniques have expanded the utility of visualization-based approaches, they are not always represented in a spatially explicit manner. Spatially explicit quantification of perceived landscape values and functions while accounting for change over time is a valuable step toward improving representation of landscape perceptions in land change research $(n=118)$. Predictive models $(n=24)$, participatory GIS $(n=22)$, and continuous flows of volunteered geographic data from social media $(n=3)$ may provide opportunities for understanding how landscape perceptions vary among diverse stakeholders across space and time. Mapping approaches have been emerging rapidly with advancements in ecosystem services research, where landscapes are mapped in terms of their perceived social values and functions $(n=53)$. Maps are particularly powerful analysis and communication tools that may be well suited for integrating landscape perceptions in land change science [36]. In the following sections, we reflect on emerging techniques related to quantifying spatial and temporal dynamics in landscape perceptions relevant to land change research.

\footnotetext{
${ }^{1}$ We collected all peer reviewed academic articles containing the keywords "landscape" and "perception" on the Web of Science resulting in 3497 records. To eliminate studies not directly addressing landscape perception we filtered out medical journal articles $(n=1211)$. We also chose to limit our assessment to journals directly concerned with the landscape perception topic, omitting those with fewer than five articles pertaining to these keywords $(n=1044)$. The abstract and title of the remaining articles $(n=1242)$ were further scanned to discard irrelevant studies and evaluate specific methods and techniques employed for a total of 584 articles. We did not include tangentially related terms akin to perception such as "cultural value", "sense of place", and "esthetic value", often used in other research communities for investigating similar phenomena, as we felt that they deviated from our main focus of investigation. While inclusion of such terminology would have resulted in a comprehensive collection of landscape values research, our search including these terms resulted in few relevant studies and a variety of journals that did not pertain to landscape and land change related topics. Still, within the database a substantial number of articles $(n=61)$ addressed this terminology suggesting that we capture a portion of these different disciplinary perspectives. Data used in this analysis are available at https://doi.org/10.5066/F7T43RMR
} 

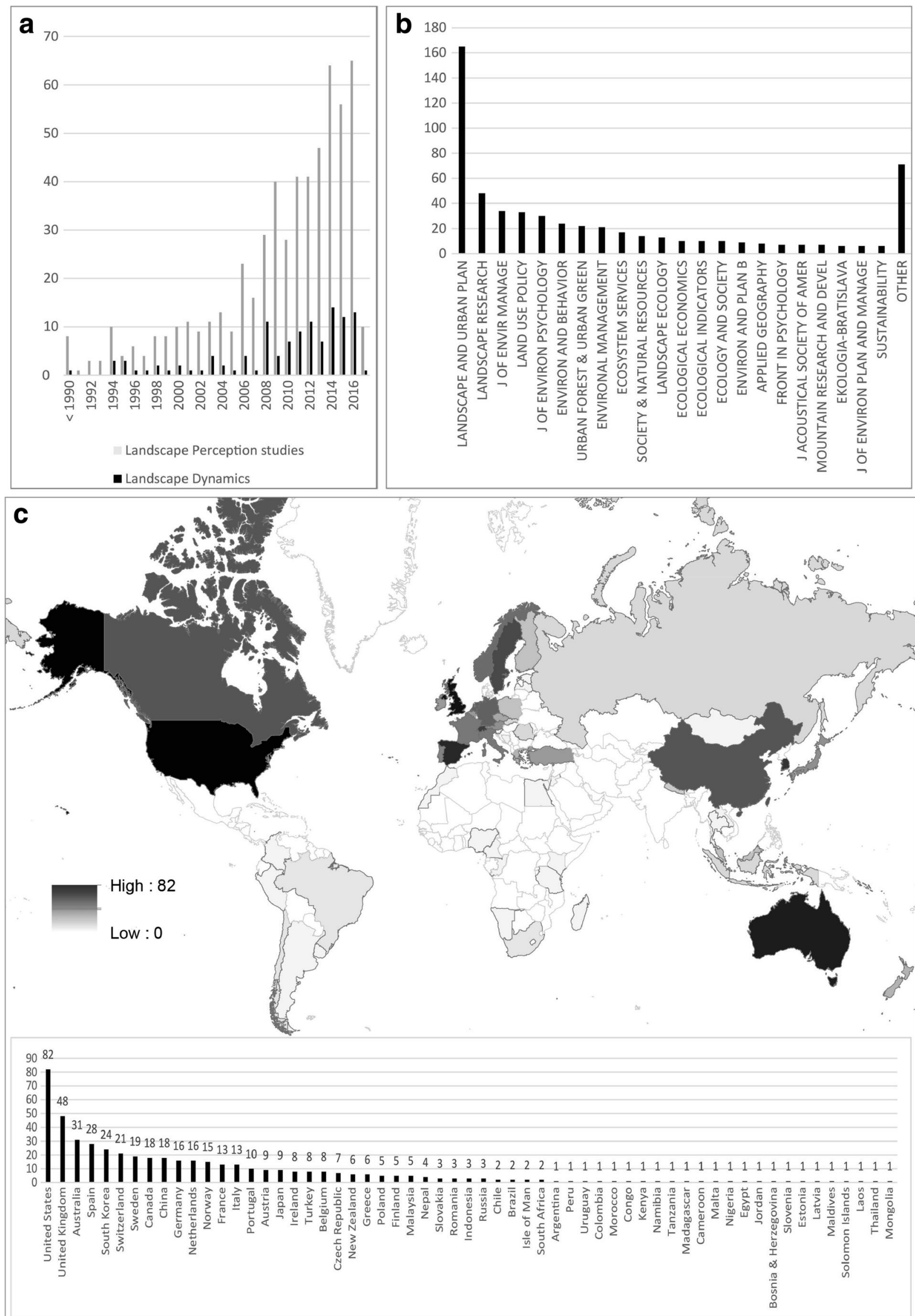
4 Fig. 2 (a) The number of journal articles containing keywords "landscape" and "perception" over time compared with those also addressing change. (b) The frequency of landscape perception research across academic journals. (c) The countries represented by landscape perception studies. Of the total 578 studies there were 105 countries and regions represented. A further 156 studies addressed non-specific locations or general landscape characteristics

\section{Photo-Based Visualizations}

By far the most prominent method for determining landscape perceptions has been through photos and photo-realistic images advanced by landscape visualization research [37•]. These visual stimuli elicit responses from the public or groups of individuals to evaluate esthetic characteristics, as well as the meanings and values associated with different landscape types, configurations, and structures [38, 39]. These types of studies have contributed to a generalized understanding of scenic beauty, cognitive and emotional responses to landscapes, and group differences in landscape perceptions. Most commonly, respondents are asked to evaluate representative photos (e.g., projected slides or prints) or photomontages depicting landscapes. Such evaluations describe the qualities associated with scenic views [40-43], appreciated landscape management [44], and location of special places [45]. Photo-editing software has added new dimensionality to these landscape evaluations by enabling realistic manipulation of existing images through adding and subtracting different landscape elements (e.g., Fig. 3). These photo-realistic images have been particularly helpful in comparison and change studies [46]. Such images enable evaluation of specific landscape elements and ensure that extraneous factors like ambient light, skyline, and cloud cover, which are factors known to influence cognitive and esthetic responses, do not influence responses [44].

While helpful in understanding the visual aspects of landscape perceptions, critiques of methods using photos have cited the dynamic and multi-sensory qualities of landscape perception, arguing for multisensory stimuli to elicit accurate responses. Zube and others [47] reviewed methods for simulating landscapes including new potential for immersive environments that included audio, visual, and dynamic stimuli. The field has made significant advancements in technology to capture the landscape experience including 3D environment technologies [48] that can be projected on large screens to simulate walking and experiencing an environment [49, 50] or immerse individuals in the designed environment using $3 \mathrm{D}$ goggles [37•]. These immersive virtual environments also enable identifying specific features associated with the respondents' values, either by recording user-provided coordinates or by tracking the users' movements [51]. Visualizations can also be made spatially explicit by coupling various types of virtual imaging techniques (e.g., photorealistic rendering, image draping, virtual worlds, and augmented realities) with features from GIS data [49].
Translation of photo evaluation into spatial representations of landscape values has proven challenging, as studies are mostly constrained to a few specific locations that are rarely representative of a broader regional makeup. Moreover, isolating specific landscape elements that can be mapped is problematic when evaluation of photos is often broad and holistic $[14,22]$. Current mapping efforts using photo evaluation have attempted to overcome this difficulty through evaluation of specific elements using stated choice [39] and contingent valuation techniques [3]. Derived values are attributed to direct spatial indices that can be mapped with cumulative spatial weights indicating locations of high landscape value. There are also efforts to investigate fundamental landscape values that can be represented as spatial indices. Qualities of tranquility, complexity, mystery, coherence, openness, smoothness, ease of motion, and heterogeneity that can be represented directly or indirectly through spatial data and metrics have been extensively investigated for their importance to people [41-43].

\section{Participatory Mapping}

Spatial representations of perceived landscape values have been sought as a means of including such values in resource management and planning processes, notably those that include ecosystem services assessment and valuation [52, 53•]. Mapping perceived social values for landscapes was initiated by Brown and others [54] who paired a value-allocation exercise based on a validated forest values typology [55] with a mapping exercise in a public attitude and preference survey. This mapping exercise was an example of participatory mapping, where multiple individuals contributed to the creation of the map [53]. Participatory mapping techniques also include participatory GIS, whereby GIS technology is used to capture spatial information during a participatory process [56]. Today many examples exist of public attitude and preference surveys used to gather the spatial and non-spatial data needed to map social values across the landscape. The maps produced with these data have evolved from representations with points [57-59] and polygons [60], to continuous value-intensity surfaces derived from statistical models [61, 62].

Interpolated point-density maps have been useful for exploring the relationships among landscape values and comparing perceptions of landscape characteristics, management prescriptions, and prevailing public uses [55]. Using statistical models to describe the relationship between perceived values and other landscape characteristics enables a more detailed understanding of which landscape features contribute to perceived value. In addition, this approach has the important advantages of yielding continuous value-intensity surfaces across the landscape $[62,63]$, the possibility to extend or transfer results beyond the original study area $[64,65]$, and 

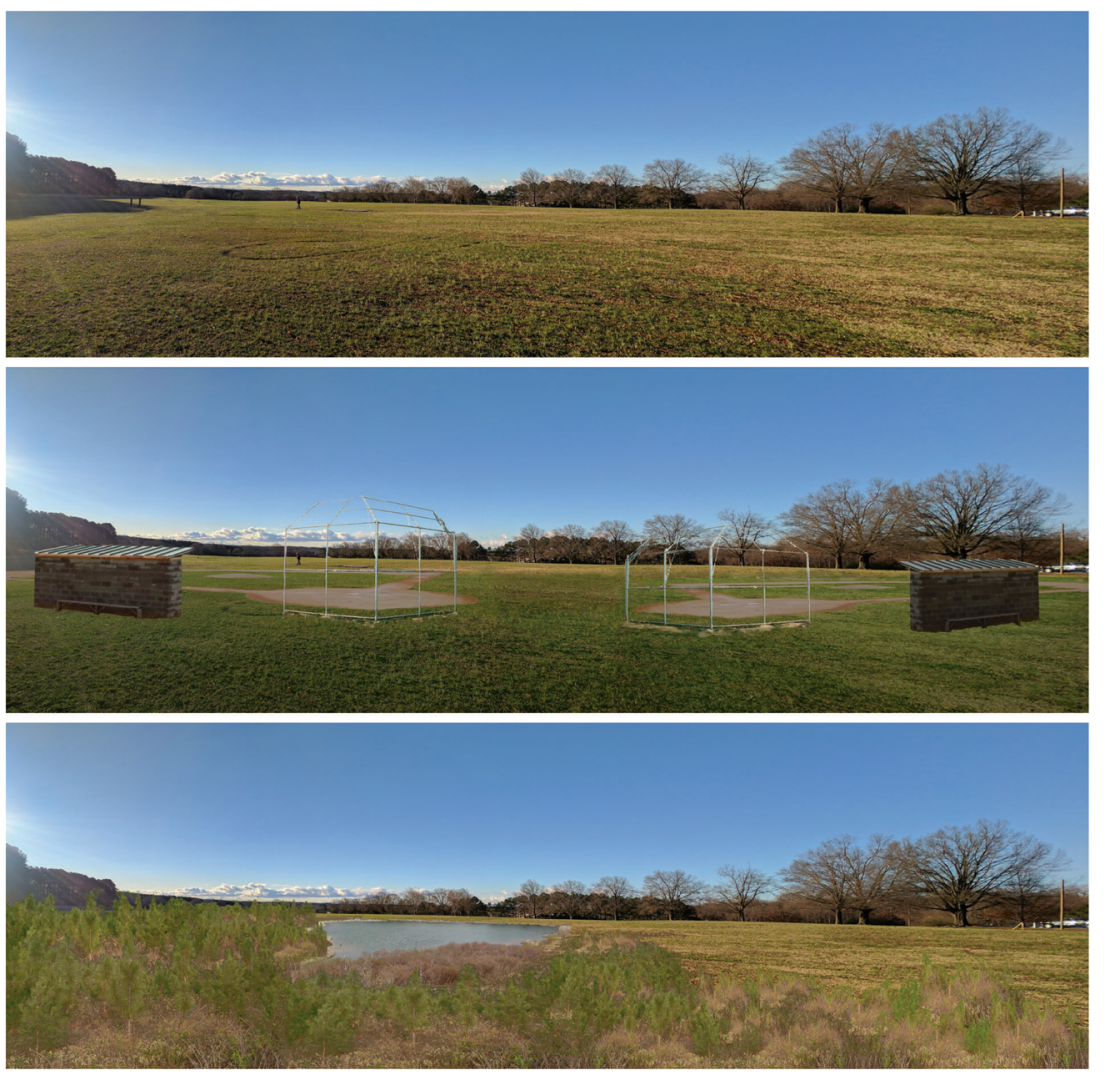

Fig. 3 A common technique used in photo-based evaluation is the application of photo manipulation for comparing different visual outcomes that may represent different scenarios of development and esthetic differences. In this example, we show different developments for Dorothea Dix Park in Raleigh, NC, USA. The park was recently purchased by the State with the intention of developing the area for public use. To develop scenarios of possible park development,

the ability to consider and anticipate the effects of landscape change on perceived social values [66].

Another class of participatory mapping is concerned with uncovering the complex culturally embedded values of landscapes and locations. These techniques stress enriching geospatial and image representations with narratives and discussion that contextualize the importance of landscapes considering social values and sense of place [67, 68]. For instance, Fagerholm and others [67] asked members of the Matemwe tribe to delineate different ecosystem services on aerial photographs combined with in-depth interviews to understand different values of the landscapes around their community in Zanzibar. Illustrations have been used in a similar fashion helping to explain the attraction or danger of landscapes to children [69]. Such methodologies offer rich information that can be difficult to articulate, for example describing indigenous peoples' understanding and deep connection with places and landscapes [53•, 70].

Geographic literacy and spatial awareness can be an issue when collecting spatially explicit impressions of landscapes. Participants may need to be acquainted with the medium of different elements were added to or subtracted from a panoramic photo of a location that is being considered for redevelopment (top image). The bottom image was augmented by adding a lake and regrowth of longleaf pine in what can be considered a nature development scenario, while in the middle image we add baseball diamonds to show the visual qualities of a recreation scenario.

spatial data collection, require aid in orienting themselves, or may be unfamiliar with wider geographic scopes given their individual mobility [67]. Issues related to participatory mapping also include translating seemingly non-tangible features like sense of place into discrete location-specific representations (citation in "Research directions and challenges" section). Participants may be unwilling or find it difficult to discretize features and areas related to, for example, a deep emotional connection or sacredness, due to the fuzziness of such cognitive links or to protect locations from disturbance caused by development or increased usership [71].

\section{Mapping with Volunteered Geographic Information}

Techniques for harvesting publicly available volunteered geographic information (VGI) from the web and social media present novel ways to evaluate interactions with and impressions of landscapes. VGI obtained through public engagement, as in citizen science initiatives, may likewise be a source of spatially explicit social data that has scarcely been leveraged [72]. Until recently, obtaining perception data required 
intensive data collection efforts through researcher-led surveys, interviews, or stakeholder engagement [53•]. These efforts have provided important insights across numerous locations, but their geographic extent has been limited. Moreover, challenges remain for eliciting accurate responses in the survey format, where positionality and warm-glow effects may influence responses, inflating values or perhaps eliciting artificial appreciation [45]. VGI presents a data source that is widely geographically representative [73•] and uniquely absent of researcher influence on content or evaluation [74]. While use of VGI in map creation may be considered one type of participatory mapping [53•], we consider it separately here due to the unique potential of these methods to contribute to mapping landscape perceptions.

Social media is perhaps the largest source of VGI providing data regarding social values and uses of the landscape. Finding ways to harness these data, Van Zanten and others [73•] recently used georeferenced social media posts of photos and comments to map landscape values across most of Europe. The study's confirmation of the similarity of maps from different social media platforms (Panoramio, Flickr, and Instagram) indicates that crowdsourcing this type of data provides a reliable indicator of landscape perceptions. Additional efforts have reiterated the applicability of social media for understanding tourism appreciation $[75,76]$, cultural ecosystem services [77, 78], and other perceived landscape values [79]. The geographic locations represented in these data, and the photos and commentary volunteered on platforms like Instagram, provide valuable information about intensity of use at specific locations and the objects being appreciated (e.g. landscape, flora, or fauna). Content density can be used to evaluate associated landscape characteristics [73 $76,77]$ while photo interpretation and content analysis can give rich qualitative information on specific landscape values [79].

We provide a simple illustration of spatial capabilities of georeferenced social media by conducting a viewshed analysis of locations of photos uploaded to the Panoramio website along a transect starting on the Front Range of the Rocky Mountains near Boulder, CO, USA. Using a digital surface model based on lidar that captures topography and tree canopy, we were able to estimate the cumulative viewing area of visitors who have contributed landscape photos to the photosharing site (Fig. 4). Points of interest include the mountain peaks of the Front Range, as well as Sugarloaf and Bald Mountain Park, which are popular recreation areas. Despite being scenic, the Lee Hill area was viewed and photographed less frequently.

While a promising data source for understanding humanenvironmental interactions, questions surrounding the representativeness of VGI remain. Devising techniques for assessing who is contributing photos and content would be valuable for evaluating their effectiveness as an indicator of landscape perception [73•]. Filtering relevant data will also be an increasing challenge as contributions to social media grow; the prevalence of non-landscape-related content (e.g., selfies or political content) requires sifting through these data to address specific study needs.

\section{Integrating Landscape Perceptions in Land Change Research}

Spatially explicit information about human perceptions may enhance land change research in a number of ways. First, perceptions are integral to describing the process of landscape change, including feedbacks and variability in landscape dynamics. Approximating locations where change coincides with different landscape perceptions is essential to understand this process fully. Second, recognizing diversity in landscape perceptions across space can inform planning efforts, ultimately influencing land change outcomes. Finally, spatial representations of landscape perceptions can be incorporated into land change models as a portion of the behavioral assumption driving decisions. Inclusion of human perceptions can improve representation of human decision making in processbased models and may prove useful for projecting potential land change outcomes. In the following sections, we describe recent applications where georeferenced landscape perception data have been integrated within and added value to land change studies.

\section{Describing Land Change Processes}

Recent studies have integrated spatial representation of landscape perceptions to improve descriptions of the land change process. Many of these studies combine quantitative and qualitative analysis techniques, including surveys, interviews, participatory workshops, and land change mapping from remote sensing. These studies examine the pathway from human perception to action and landscape change, as well as the feedback from landscape change to human perceptions of change, its impacts, and subsequent actions.

Individual location choices are one way in which landscape perceptions may affect landscape change, such as deciding where to build a house, a trail, or a new development. In combination with biophysical land change analysis, quantifying the regional landscape perceptions of local stakeholders can be used to identify land change drivers and improve interpretation of change [80, 81]. Mapping landscape values can also be a useful approach for understanding this process. For example, amenity migration is a leading driver of landscape change in the U.S., where individuals choose to build or purchase homes based on the landscape's esthetic or other values. Vukomanovic and Orr [82] used a predictive model of scenic values to understand residential site locations in the Intermountain West, finding that locations with 
Fig. 4 Social media mapping analysis showing the locations of volunteered photos and modeled viewing area along a transect of the Colorado Front Range

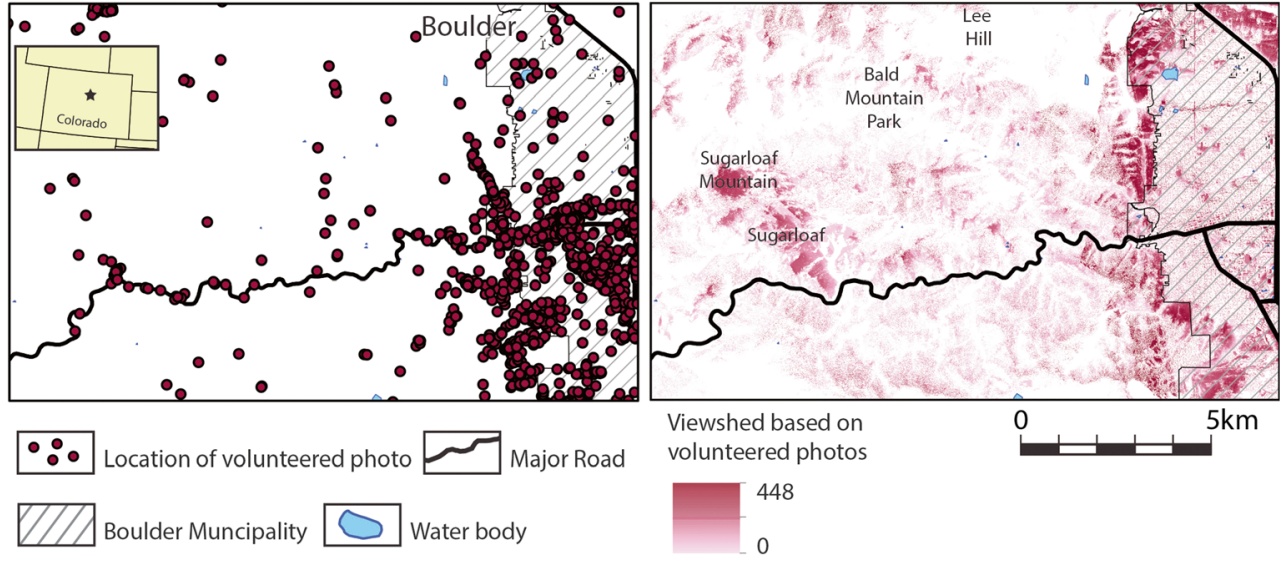

greater scenic diversity experience greater than expected levels of development. In an urban context, Dorning [31] found that landscape perceptions had a greater influence on decisions to sell undeveloped land than measured environmental indicators. The study used a questionnaire to assess landowner perceptions of georeferenced forested properties matched to field survey and land-cover data from the same locations (as demonstrated in Fig. 5). Taking a stakeholder engagement approach, Lamarque and others [83] used a map-based role playing game to understand how farmers' perceptions of ecosystem services in the landscape affected their land-management decisions under alternative scenarios. The insights gained through these studies could not have been accomplished without spatially explicit landscape perceptions information.

In a study of the land change process and feedbacks, Meyfroidt [84.] examined forest-cover change in Vietnam over time using remote sensing combined with participatory mapping and interviews. The addition of participatory mapping allowed identification of locations of local management actions, which may have been driven by forest change. Additional recent studies have examined human perceptions of landscape change, how perceptions compare with quantifiable measures, and how those perceptions lead to changes in decisions (feedbacks). For example, a study in the Black Forest of Germany demonstrated that perceptions of forest expansion did not necessarily match biophysical increases, but were based more on visible effects and included noticeable time lags [85]. Feedbacks were apparent in this system where public perceptions of forest encroachment drove open-space preservation efforts at local and regional levels, though most were largely unsuccessful. Lai and Kreuter [86] found similar responses in the Hill Country of Texas in the U.S., where perceptions of change affected an individual's desires to conserve or retain their properties, depending on their level of place attachment. Perception of change and its impacts may also drive changes in land-use and land-management practices in response to perceived degradation, as demonstrated by studies of stakeholders in Costa Rica [87], Uganda [88], and
Ethiopia [89]. These studies generally used surveys and interviews to understand the link between landscape change and stakeholder responses within specific regions, without quantitatively assessing intermediate effects on perception of landscape values.

\section{Supporting Landscape Planning}

A number of studies have stressed the importance of considering relevant ecological and socioeconomic values in pursuance of sustainability in landscape planning [18, 19, 90, 91]. Landscape planning is also an avenue through which human perceptions may influence landscape change. Since social values do not always align with biophysical or expert assessments, it is beneficial to incorporate explicitly the diverse perceptions and values of stakeholders in planning endeavors $[19,92]$. Accounting for public perceptions of specific landscapes can improve receptiveness of those affected by management activities and may result in changing landscape plans to better meet the needs of stakeholders [30, 93, 94].

Despite the importance of including landscape perceptions in planning, representing the diverse values of stakeholders remains a challenge [95]. For example, although diversity was a recognized component of landscape character assessments used for planning in the United Kingdom, these assessments often failed to represent the values of residents, instead being based on the values of an "objective outsider" [96]. However, researchers have explored methods for improving the representation of diverse values in landscape planning using spatially explicit approaches. Bryan and others [97] suggested a method using mapped social values to target priority areas for planning to protect ecosystem services in South Australia. Priority locations were identified based on the abundance, diversity, rarity, and threats to stakeholder values in the landscape. Rogge and others [98] evaluated a GIS planning instrument to assess the visual impacts of large-scale greenhouse developments on the landscape in Flanders, Belgium. Public perception of the esthetic impacts of greenhouse 


a Perception \& Action
Question 1. I value the forest because I enjoy the
forest scenery, sights, sounds, smells, etc.
Agree
5
Question 2. The trees on my property, on
average, are...
A. Very old (100+ Years)
B. Somewhat old (50-100 Years)
C. Somewhat young (10-50 Years)
D. Very young (Less than 10 Years)
Question 3. My forest is surrounded by...
A. Mostly development
B. Mostly farmland
C. Mostly other forest
D. A mix of landscape types
Question 4. In the last 5 years, I have performed
the following management activities on my
property...
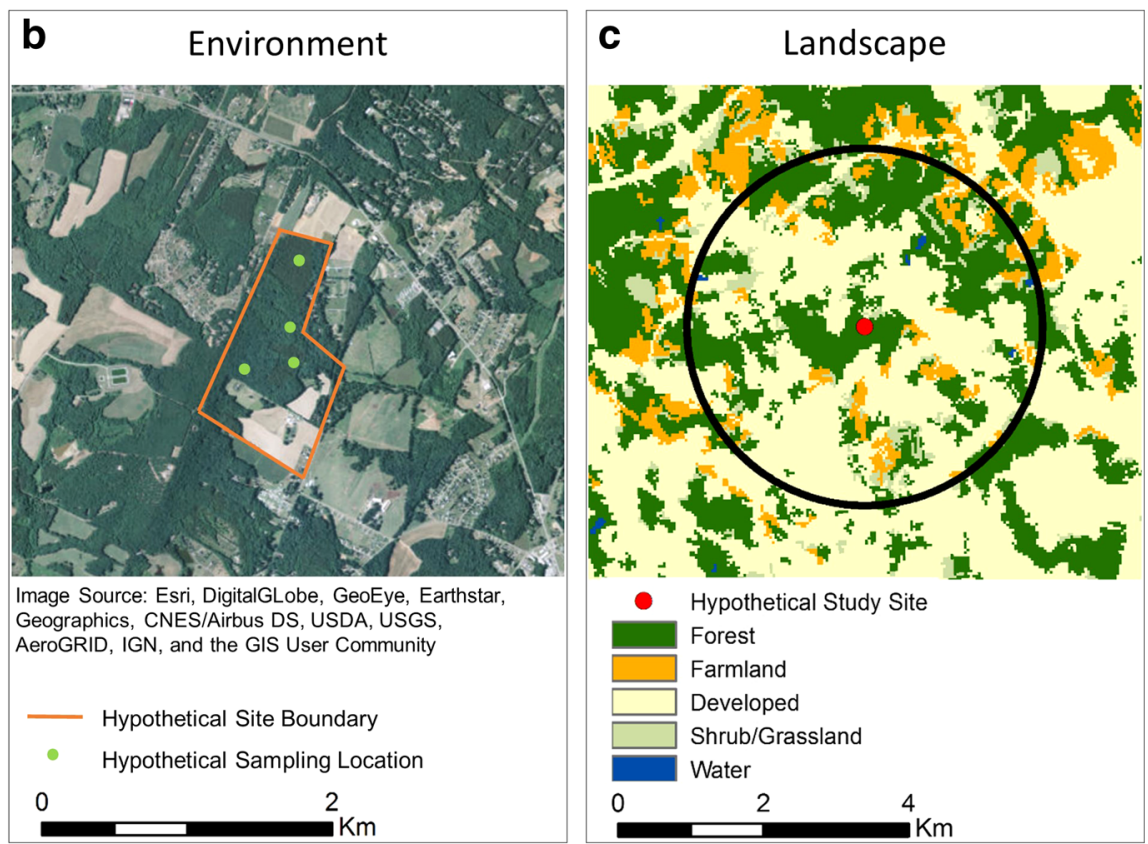

Fig. 5 Example of matching social and environmental data for studying land change processes. (a) Landowners may respond to surveys regarding a specific site shown in a map (b), including their value perceptions [45], landscape perceptions, and management activities on that land. Those may be matched to (b) field data collected at the site and (c) landscape

level data, such as land-cover types and patterns within a particular radius ( $2 \mathrm{~km}$ radius shown) of the study site. All examples shown here are hypothetical cases and do not accurately represent the landscape or its attributes

construction had led to resistance and the relocation of these developments to more publicly desirable locations. Reed and Brown [99] suggested a method called values suitability analysis to incorporate mapped human perceptions of value into traditional forest planning processes and Brown and Weber [100] followed by a participatory mapping methodology to inform national park planning. All of these methods utilize perceptions mapping approaches to incorporate social values in landscape planning.

Statistically derived hotspot analyses of perceived landscape values provides an additional means of identifying locations of shared values or conflicts [57, 58, 101, 102], as well as a method for identifying social-ecological hotspots when coupled with biophysical information [103-105]. The combination of biophysical and cultural information to inform landscape management has proved challenging because of the lack of a common metric of value, but hotspot maps of ecosystem services production provide one means of integrating these disparate value types. Identifying social-ecological hotspots has the potential to reveal natural resource management synergies and conflicts with distinct management implications, including which areas are most suitable for conservation and which are most suitable for more intensive human uses. To date, however, there is little evidence that social-ecological hotspots have been used for actual decision support in landuse planning [106].

With the exception of viewshed mapping, there are few examples of integrating mapped landscape perceptions in planning efforts. To the best of our knowledge, many of the platforms described here for including social values in planning have not been tested in practice. Collecting primary data related to human perceptions may be too costly for many planning projects, making VGI a potentially viable way to integrate perceptions in planning using secondary data. Balancing biophysical landscape functions with diverse human perceptions of value is likely to remain a challenge despite improvement in assessment tools [22, 24] since landscapes are limited in their ability to provide for the needs of all user groups [107].

\section{Modeling Landscape Change}

Land change models are valuable tools used by researchers and planners to understand how landscapes have and may be changing, including analysis of the potential impacts of those changes. The representation of human-environment interactions and feedbacks in land change models remains a challenge and may be facilitated in part by including the role of landscape perceptions. Including perceptions in process-based models allows exploration of how perceptions influence decision making and landscape outcomes. Models designed to make projections may be improved by accounting for landscape perceptions in addition to biophysical indicators. Land change models may also be applied to anticipate how potential change may reciprocally influence landscape perceptions, providing some insight into the social impacts of alternative 
land change scenarios. Mapped landscape perceptions may be particularly beneficial for use in models given the spatially explicit nature of many modeling environments.

Among process-based land change models, agent-based models (ABMs) are a promising approach for incorporating varying landscape perceptions of individuals and groups, including feedbacks between decisions and landscape change [108]. ABMs simulate actions of individual or societal agents based on their characteristics, as well as interactions with other agents and the environment. For example, Robinson and Brown [109] explicitly incorporated mapped landscape perceptions (esthetic quality) into an ABM of exurban development and Matthews [110] incorporated human perceptions into an $\mathrm{ABM}$ framework for evaluating farming management practices. The ability of ABMs to include heterogeneous actors would allow exploration of how individual decisions based on varying perceptions may collectively influence landscapes. While progress has been made toward improving representation of human decision-making in ABMs at local scales, parameterizing broader scale models remains a challenge $[111,112]$. Mapping of landscape perceptions may facilitate progress in this area by providing regional scale inputs of social values.

Models designed for making projections of potential future landscape change commonly use biophysical indicators to create suitability maps, identifying where change is likely to occur [113]. Since land-management decisions involve human decision making, mapped perceptions may be appropriate for capturing the influence of social values on landscape suitability in combination with biophysical measures. A number of land change modeling applications have incorporated surrogates for social values (e.g., distance from road or waterways) in suitability analysis (e.g., [114]). Viewshed maps have also been incorporated into residential development models [115], demonstrating how views affect land change outcomes. New methods for mapping landscape perceptions may provide an opportunity for exploring how additional social values may affect land change outcomes. Scenario analysis can also be used to project change based on alternative perceptions of landscape values. Claessens and others [116] coupled land change and soil erosion models to understand how feedbacks between land-use change and soil erosion influenced landscape outcomes, including a scenario that accounts for the influence of farmers' perceptions of landscape erosion on expected land-use practices. Maps of landscape perceptions pave the way for understanding how landscapes may change to prioritize different values.

Anticipating perceived landscape values under alternative future landscape conditions provides a promising means of avoiding conflicts between different stakeholder groups. Augmented photos and other visualizations have been used to evaluate and discuss alternative planning options for specific locations [e.g., 117], including examination of the impacts of potential land-management options on people's perceptions [e.g., 46, 118, 119]. Spatially explicit land change scenarios can also be translated into 3D landscape visualizations that can then be evaluated by stakeholders $[120,121]$. Further, social-value maps based on landscape characteristics readily lend themselves to this type of geographic scenario analysis. For example, Zank and others [122] coupled land change models with esthetic models to quantify potential impacts of change on landscape scenic quality and Sherrouse and others [66] examined the impacts of road-network expansion on the spatial distribution and intensity of esthetic and recreation values. Results from this analysis further permitted an assessment of tradeoffs between the two value types to reveal areas of conflict and agreement, and a further accounting of how these tradeoffs varied across different user groups. Understanding these outcomes would not be possible without predictive spatial models of landscape perceptions.

\section{Research Directions and Challenges}

Despite recent advances in quantifying and mapping landscape perceptions, there remain relatively few examples of integrating spatial representations of perceptions into studies of land change processes, planning, and models. Our findings show that the majority of research that has integrated landscape perceptions focuses on esthetics and views. New mapping techniques allow exploration of additional perceived landscape characteristics. These maps could be used to relate human perceptions and social values to mapped locations of landscape change and their biophysical attributes. This will ultimately improve our understanding of land change processes and help us to anticipate locations of future change based on social factors. The impacts of these factors on landscape change can be further explored through integration in process-based land change models, an area that appears relatively understudied given the apparent suitability of mapped perceptions as modeling inputs. Models can be used for exploring how individual decisions based on varying perceptions may collectively influence regional landscape patterns, as well as projecting scenarios of future change based on varying prioritizations of landscape values. Frameworks that incorporate mapped landscape perceptions are also promising avenues for including perceptions in planning; documented testing of these frameworks in practice might facilitate their further use. However, mapping landscape perceptions and integrating them into research and practice are not without their challenges, including consideration of multisensory inputs, the scale of analysis, representation of diverse groups, and the validity and reliability of those representations.

Broadening research regarding human perceptions of landscapes to include non-visual perception and esthetics will likely improve our understanding of landscape perceptions and 
values. People rely on other senses to perceive and interpret landscapes, but these are infrequently the focus of perception studies [123]. Immersive methods can potentially capture the specific effects of other senses on landscape perceptions. Considerable effort has been made in understanding how soundscapes influence landscape perceptions as an important cognitive stimuli $[124,125]$. Considering other senses including olfaction, touch, and feel would enhance our understanding of the effects of landscape perceptions on landscape change. While multisensory impacts are easily observed in situ, new multisensory immersive environments would help in isolating specific sensory elements related to our values of specific spaces. Future immersive environments that allow for comparing the fragrant aromas of flowers with the smell of industrial farms that enable you to feel the wind of an open meadow compared to the heat of a closed forest, hear the screech of a predatory bird juxtaposed by highway traffic, would enhance our understanding of landscape perception to encompass visual, as well as sensory tradeoffs. Mapping these multisensory "scapes" will require innovation including new sensors, data collection techniques, and spatial approximations that capture these qualities.

Mapping approaches in general will need to address limitations related to their ability to adequately represent landscape perceptions. In particular, approaches for assessing spatial accuracy are required as is evident by the rarity of their evaluation in perception studies. Our ability to capture, and then extrapolate, non-tangible human perceptions across space in a tangible, quantitative map has not been sufficiently addressed [53•]. Assessing the validity and reliability of these maps is a challenge [53•] due to the dynamic and variable nature of perceptions, as well as a scarcity of independent and longitudinal data that capture these perceptions across diverse groups. However, conducting these assessments is not impossible and helps legitimatize the use of mapped perceptions in research [126]. In addition to the challenges of capturing perceptions across space, mapping approaches are also vulnerable to the pitfalls of traditional survey methods, including issues with participation rates and sampling bias [106]. The choice of spatial and temporal scale for analysis should also be given some attention [see 127, 128] in relation to accuracy of mapped perception, as human perception of the landscape occurs at a particular human scale, or perceptible realm $[14,22]$, but may still affect landscapes at multiple scales. Regional mapping generally occurs at scales that are broader than the human perceptible realm. Further research is needed to understand whether these maps capture perceptions as intended, as well as how and to what degree these broader scale patterns of perception patterns influence land change processes.

Addressing the social representativeness of maps presents a specific challenge. While mapping and spatial modeling of landscape perceptions have proven useful for identifying trends and defining locations of shared landscape values, these values may not be consistent across the entire population or within different stakeholder groups. A single map will not capture the full range of landscape perceptions within any given population [129, 130]. Additionally, landscape perceptions are formulated by individuals in relation to a specific place and are not always generalizable from one region to another [64]. Our evaluation of recent studies focused on landscape perceptions demonstrates uneven spatial representation across space (Fig. 2). Shared and divergent perceptions among populations and across regions need to be considered in describing, planning, and modeling landscape change. This can be further complicated when land change drivers and impacts are not collocated. Despite recognition of these and other sources of uncertainty in perceptions assessments, this uncertainty is frequently ignored when translated into a spatial representation. Variation in perceptions can be captured by using multiple maps for different user groups and by mapping uncertainty associated with mapped values (e.g., $[131,132])$. Lechner and others [133] have devised a framework for characterizing uncertainty propagation when incorporating spatially referenced social data in conservation planning, including uncertainty in the spatial distribution of social and cultural values. Hamel and Bryant [134] also summarize solutions and techniques for including uncertainty in ecosystem services maps. The methods suggested by these studies provide a valuable starting point for accounting for the uncertainty of social data in land change research.

VGI may provide a source of data that can partially validate local and regional scale findings due to their wide use and spatiotemporal representativeness through crowdsourcing, social media, and citizen science initiatives. Abundant VGI data likely capture variation across geographic locations and differences between some social groups [73•]. However, care should also be taken in using these data as their reliability and validity have not been fully assessed [135], especially in terms of the content relevance, and the prevalence of specific user-groups contributions. Such comparison across methods and in diverse locations would certainly add to our understanding of accuracy across these spatial methods for assessing perceptions. While technologies that collect VGI will undoubtedly advance, likely giving access to novel and more accurate data, the ability to obtain these data may change due to privacy issues, user preferences, and increased commodification of such content [136]. Moreover, capturing representative data from social media platforms, when usership will likely shift considerably given novel and new applications, will be a challenge.

Despite issues with access and representativeness of social media contributions, they present a relatively untapped source of data that, beyond validation, can further enhance our understanding of human interactions with specific locations. The rich content volunteered by contributors represents a wealth of 
data with many research applications. Text mining of included captions and posts can identify how landscapes are being experienced (e.g., beautiful or repelling) and help summarize different human-nature interactions and attitudes (e.g., Arcadian, wild, or functional), while contributed photos can be analyzed to understand general models of esthetic values. Image recognition machine learning algorithms might be employed for photo assessment automating the classification of photo content [137]; the large amounts of data will invariably require advanced spatial analysis and efficient computational capabilities that reduce processing times. Citizen science initiatives may be similarly powerful for collecting large quantities of spatially explicit longitudinal perception data. Given the success of ecological data collection efforts via citizen science [138], and the opportunity for close sciencepublic engagement in such initiatives, the potential for surveying social data (e.g., perception of urban developments) seems promising. However there are currently few documented examples of collecting social data using citizen science despite early successes [72]. Concerns about protecting the personal details of volunteer participants [72] and lack of tools for engaging the public have been cited as major barriers to such initiatives [135]. Still, engagement through citizen science might be a way to bridge the gap between community landscape perceptions and actual landscape outcomes through input from multiple stakeholders. Further, the use of VGI is also less costly than traditional survey techniques, making VGI more accessible for many researchers or planners.

While emerging technologies will undoubtedly shape future research on landscape perceptions, land change scientists will need to determine the degree to which spatial representations of landscape perceptions can aid in their research. The process of land change is certainly influenced by perceptions; however, the contribution to land change decisions or patterns may be relatively small in some contexts, or sufficiently captured by economic proxies commonly used in model simulations [139]. Depending on the goals of the study, land change scientists might forego adding spatial layers or conceptualizations of perceptions that increase effort and complexity. However, detailed investigations of land change processes, including those incorporating agent-based models, will likely benefit from these emerging technologies as they enhance our ability to map social determinants of land change [8].

\section{Conclusions}

Landscape perceptions are a component of the human decision-making process governing landscape change. New techniques for understanding and mapping diverse perceived landscape values, preferences, and functions across space and time provide an exciting and novel opportunity for including them in land change research. These maps do have their limitations, with questions regarding whose values are being represented and how well they can be portrayed at broad spatial scales. However, with these tools we may gain new insights into the role of diverse landscape perceptions in land change processes, including their influences on landscape change, emergent landscape patterns, and reciprocal impacts of change on social perceptions of the landscape. These insights can further be incorporated in models of landscape change and may prove useful in applied landscape science for planning sustainable landscapes. The playing field is changing and capacity is building for improving representation of these human dimensions of the landscape in landscape ecology and land change research.

Acknowledgements The authors thank B. C. Sherrouse and two anonymous reviewers for thoughtful and constructive comments that helped improve the quality of this manuscript. This research was supported in part by the U.S. Geological Survey Land Change Science Program. Any use of trade, firm, or product names is for descriptive purposes only and does not imply endorsement by the U.S. Government.

\section{Compliance with Ethical Standards}

Conflict of Interest On behalf of all authors, the corresponding author states that there is no conflict of interest.

\section{References}

Papers of particular interest, published recently, have been highlighted as:

- Of importance

1. Meyfroidt P. Environmental cognitions, land change, and socialecological feedbacks: an overview. J Land Use Sci. 2013;8:34167. Detailed explanation of the role environmental cognitions (including perceptions) in land-use systems, with a review of theories relating human behavior to environmental change

2. Zube EH, Sell JL, Taylor JG. Landscape perception: research, application and theory. Landsc Plan. 1982;9:1-33.

3. van Zanten BT, Verburg PH, Scholte SSK, Tieskens KF. Using choice modeling to map aesthetic values at a landscape scale: lessons from a Dutch case study. Ecol Econ. 2016;130:221-31.

4. Van Berkel DB, Verburg PH. Combining exploratory scenarios and participatory backcasting: using an agent-based model in participatory policy design for a multi-functional landscape. Landsc Ecol. 2012;27:641-58.

5. Brown DG, Robinson DT. Effects of heterogeneity in residential preferences on an agent-based model of urban sprawl. Ecol Soc. 2006;11:46.

6. Palmer JF. Using spatial metrics to predict scenic perception in a changing landscape: Dennis, Massachusetts. Landsc Urban Plan. 2004;69:201-18.

7. Schroth O, Pond E, Sheppard SRJ. Integration of spatial outputs from mathematical models in climate change - visioning tools for community decision making on the landscape scale. DLA-Digital Landsc Archit. 2011:246-55. 
8. An L. Modeling human decisions in coupled human and natural systems: review of agent-based models. Ecol Model. 2012;229: $25-36$.

9. Liu J, Dietz T, Carpenter SR, et al. Coupled human and natural systems. Ambio. 2007;36:639-49.

10. Verburg PH, Soepboer W, Veldkamp A, Limpiada R, Espaldon V, Mastura SSA. Modeling the spatial dynamics of regional land use: the CLUE-S model. Environ Manag. 2002;30:391-405.

11. Meentemeyer RK, Tang W, Dorning MA, Vogler JB, Cunniffe NJ, Shoemaker DA. FUTURES: multilevel simulations of emerging urban-rural landscape structure using a stochastic patch-growing algorithm. Ann Assoc Am Geogr. 2013;103:785-807.

12. Parker D, Manson S, Janssen M, Hoffmann M, Deadman P. Multiagent systems for the simulation of land-use and land-cover change: a review. Ann Assoc Am Geogr. 2003;93:314-37.

13. Zube EH. Perceived land use patterns and landscape value. Landsc Ecol. 1987;1:37-45.

14. Nassauer JI. Culture and changing landscape structure. Landsc Ecol. 1995;10:229-37.

15. Verburg PH. The representation of human-environment interactions in land change research and modelling. In: Underst. Soc. Nat. Resour. Forg. New Strands Integr. Across Soc. Sci.; 2014. p. 161-177. A well-articulated discussion of considerations and research approaches for integrating human dimensions in land change research.

16. Bürgi M, Hersperger AM, Schneeberger N. Driving forces of landscape change - current and new directions. Landsc Ecol. 2004;19:857-68

17. Wu J. Landscape of culture and culture of landscape: does landscape ecology need culture? Landsc Ecol. 2010;25:1147-50.

18. Opdam P, Nassauer JI, Wang Z, Albert C, Bentrup G, Castella JC, et al. Science for action at the local landscape scale. Landsc Ecol. 2013;28:1439-45.

19. Ryan RL. The social landscape of planning: integrating social and perceptual research with spatial planning information. Landsc Urban Plan. 2011;100:361-3.

20. Turner B, Lambin E, Reenburg A. The emergence of land change science for global environmental change and sustainability. Proc Natl Acad Sci U S A. 2007;104:20666-72.

21. Hersperger AM, Gennaio M-P, Verburg PH, Bürgi M. Linking land change with driving forces and actors:four conceptual models. Ecol Soc. 2010;15:1-19.

22. Gobster PH, Nassauer JI, Daniel TC, Fry G. The shared landscape: what does aesthetics have to do with ecology? Landsc Ecol. 2007;22:959-72.

23. Stamps AE. Demographic effects in environmental aesthetics: a meta-analysis. J Plan Lit. 1999;14:155-75.

24. Stephenson J. Many perceptions, one landscape. Landsc Rev. 2003;11:9-30.

25. Keulartz J, Van Der Windt H, Swart J. Concepts of nature as communicative devices: the case of Dutch nature policy. Environ Values. 2004;13:81-99.

26. Buijs AE, Pedroli B, Luginbühl Y. From hiking through farmland to farming in a leisure landscape: changing social perceptions of the European landscape. Landsc Ecol. 2006;21:375-89.

27. Kenter JO, Reed MS, Irvine KN, et al. Shared values and deliberative valuation: Future directions. Ecosyst Serv Issue. 2016 :358371

28. Brown G, Smith C, Alessa L, Kliskey A. A comparison of perceptions of biological value with scientific assessment of biological importance. Appl Geogr. 2004;24:161-80.

29. Verschuuren B. An overview of cultural and spiritual values in ecosystem management and conservation strategies. International Conference on Endogenous Development and BioCultural Diversity. 2006 :299-325.
30. Gobster PH, Westphal LM. The human dimensions of urban greenways: planning for recreation and related experiences. Landsc Urban Plan. 2004;68:147-65.

31. Dorning MA. Landscape change and human-environment interactions: Implications for natural resource management in urbanizing areas. The University of North Carolina at Charlotte; 2014.

32. Tuan Y-F. Space and place: The perspective of experience. University of Minnesota Press; 1977.

33. Filatova T, Verburg PH, Parker DC, Stannard CA. Spatial agentbased models for socio-ecological systems: challenges and prospects. Environ Model Softw. 2013;45:1-7.

34. Henry AD, Dietz T. Understanding environmental cognition. Organ Environ. 2012;25:238-58.

35. Kaplan R. The analysis of perception via preference: a strategy for studying how the environment is experienced. Landsc Plan. 1985;12:161-76.

36. Soini K. Exploring human dimensions of multifunctional landscapes through mapping and map-making. Landsc Urban Plan. 2001;57:225-39.

37. Lovett A, Appleton K, Warren-Kretzschmar B, Von Haaren C. Using 3D visualization methods in landscape planning: an evaluation of options and practical issues. Landsc Urban Plan. 2015;142:85-94. An overview of 3D technologies for landcape planning

38. Appleton K, Lovett A. GIS-based visualisation of rural landscapes: defining "sufficient" realism for environmental decisionmaking. Landsc Urban Plan. 2003;65:117-31.

39. Van Berkel DB, Verburg PH. Sensitising rural policy: assessing spatial variation in rural development options for Europe. Land Use Policy. 2011;28:447-59.

40. Schirpke U, Hölzler S, Leitinger G, Bacher M, Tappeiner U, Tasser E. Can we model the scenic beauty of an alpine landscape? Sustainability. 2013;5:1080-94.

41. de la Fuente de Val G, Atauri JA, de Lucio JV. Relationship between landscape visual attributes and spatial pattern indices: a test study in Mediterranean-climate landscapes. Landsc Urban Plan. 2006;77:393-407.

42. Strumse E. Environmental attributes and the prediction of visual preferences for agrarian landscapes in western Norway. J Environ Psychol. 1994;14:293-303.

43. van den Berg AE, Vlek CAJ, Coeterier JF. Group differences in the aesthetic evaluation of nature development plans: a multilevel approach. J Environ Psychol. 1998;18:141-57.

44. Ribe RG. Aesthetic perceptions of green-tree retention harvests in vista views: the interaction of cut level, retention pattern and harvest shape. Landsc Urban Plan. 2005;73:277-93.

45. Van Berkel DB, Verburg PH. Spatial quantification and valuation of cultural ecosystem services in an agricultural landscape. Ecol Indic. 2014;37:163-74.

46. Soliva R, Bolliger J, Hunziker M. Differences in preferences towards potential future landscapes in the Swiss alps. Landsc Res. 2010;35:671-96.

47. Zube EH, Simcox DE, Law CS. Perceptual landscape simulations: history and prospect. Landsc J. 1987;6:62-80.

48. Daniel TC. Whither scenic beauty? Visual landscape quality assessment in the 21st century. Landsc Urban Plan. 2001;54:26781.

49. Appleton K, Lovett A, Sünnenberg G, Dockerty T. Rural landscape visualisation from GIS databases: a comparison of approaches, options and problems. Comput Environ Urban Syst. 2002;26:141-62.

50. Bishop ID, Wherrett JAR, Miller DR. Assessment of path choices on a country walk using a virtual environment. Landsc Urban Plan. 2001;52:225-37.

51. Smith JW. Immersive virtual environment technology to supplement environmental perception, preference and behavior research: 
a review with applications. Int J Environ Res Public Health. 2015;12:11486-505.

52. Daily GC, Polasky S, Goldstein J, Kareiva PM, Mooney HA, Pejchar L, et al. Ecosystem services in decision making: time to deliver. Front Ecol Environ. 2009;7:21-8.

53. Brown G, Fagerholm N. Empirical PPGIS/PGIS mapping of ecosystem services: a review and evaluation. Ecosyst Serv. 2015;13: 119-33. Overview of the state of the art PPGIS to date and how these techniques can be used to map perceptions and values

54. Brown GG, Reed P, Harris CC. Testing a place-based theory for environmental evaluation: an Alaska case study. Appl Geogr. 2002;22:49-76.

55. Brown G, Reed P. Typology for use in national forest planning. Science. 2000;46:240-7.

56. Sieber R. Public participation geographic information systems: a literature review and framework. Ann Assoc Am Geogr. 2006;96: 491-507.

57. Alessa, LN, Kliskey, AA, Brown G. Social-ecological hotspots mapping: a spatial approach for identifying coupled social-ecological space. Landsc Urban Plan. 2008;85:27-39.

58. Sherrouse BC, Clement JM, Semmens DJ. A GIS application for assessing, mapping, and quantifying the social values of ecosystem services. Appl Geogr. 2011;31:748-60.

59. Plieninger T, Dijks S, Oteros-Rozas E, Bieling C. Assessing, mapping, and quantifying cultural ecosystem services at community level. Land Use Policy. 2013;33:118-29.

60. Brown GG, Pullar DV. An evaluation of the use of points versus polygons in public participation geographic information systems using quasi-experimental design and Monte Carlo simulation. Int J Geogr Inf Sci. 2012;26:231-46.

61. van Riper CJ, Kyle GT, Sutton SG, Barnes M, Sherrouse BC. Mapping outdoor recreationists' perceived social values for ecosystem services at Hinchinbrook Island National Park, Australia. Appl Geogr. 2012;35:164-73.

62. Sherrouse BC, Semmens DJ, Clement JM. An application of social values for ecosystem services (SolVES) to three national forests in Colorado and Wyoming. Ecol Indic. 2014;36:68-79.

63. Schirpke U, Tasser E, Tappeiner U. Predicting scenic beauty of mountain regions. Landsc Urban Plan. 2013;111:1-12.

64. Sherrouse BC, Semmens DJ. Validating a method for transferring social values of ecosystem services between public lands in the Rocky Mountain region. Ecosyst Serv. 2014;8:166-77.

65. Brown G, Pullar D, Hausner VH. An empirical evaluation of spatial value transfer methods for identifying cultural ecosystem services. Ecol Indic. 2016;69:1-11.

66. Sherrouse BC, Semmens DJ, Ancona ZH, Brunner NM. Analyzing land-use change scenarios for trade-offs among cultural ecosystem services in the southern Rocky Mountains. Ecosyst Serv. 2017; doi:10.1016/j.ecoser.2017.02.003.

67. Fagerholm N, Käyhkö N, Ndumbaro F, Khamis M. Community stakeholders' knowledge in landscape assessments - mapping indicators for landscape services. Ecol Indic. 2012;18:421-33.

68. Palomo I, Martín-López B, Zorrilla-Miras P, García Del Amo D, Montes C. Deliberative mapping of ecosystem services within and around Doñana National Park (SW Spain) in relation to land use change. Reg Environ Chang. 2014;14:237-51.

69. Alexander J, Cocks ML, Shackleton C. The landscape of childhood: play and place as tools to understanding children's enviromental use and perceptions. Hum Ecol. 2015;43:467-80.

70. Klain SC, Satterfield TA, Chan KMA. What matters and why? Ecosystem services and their bundled qualities. Ecol Econ. 2014;107:310-20.

71. Abbot J, Chambers R, Dunn C, Harris T, Merode ED, Porter G, et al. Participatory GIS: opportunity or oxymoron? PLA notes. 1998;33:27-33.
72. Heiss R, Matthes J. Citizen science in the social sciences: a call for more evidence. GAIA - Ecol Perspect Sci Soc. 2017;26:22-6.

73. van Zanten BT, van Berkel DB, Meetemeyer RK, Smith JW, Tieskens KF, Vergurg PH. Continental scale quatification of landscape values using social media data. Proc Natl Acad Sci. 2016 $: 1-7$. An evaluation of social media as an indicator of landscape perceptions.

74. Goodchild MF. Citizens as sensors: the world of volunteered geography. GeoJournal. 2007;69:211-21.

75. Willemen L, Cottam AJ, Drakou EG, Burgess ND. Using social media to measure the contribution of red list species to the naturebased tourism potential of African protected areas. PLoS One. 2015;10:e0129785.

76. García-Palomares JC, Gutiérrez J, Mínguez C. Identification of tourist hot spots based on social networks: a comparative analysis of European metropolises using photo-sharing services and GIS. Appl Geogr. 2015;63:408-17.

77. Martínez Pastur G, Peri PL, Lencinas MV, García-Llorente M, Martín-López B. Spatial patterns of cultural ecosystem services provision in southern Patagonia. Landsc Ecol. 2016;31:383-99.

78. Tenerelli P, Demšar U, Luque S. Crowdsourcing indicators for cultural ecosystem services: a geographically weighted approach for mountain landscapes. Ecol Indic. 2016;64:237-48.

79. Dunkel A. Visualizing the perceived environment using crowdsourced photo geodata. Landsc Urban Plan. 2015;142:173-86.

80. González-Puente M, Campos M, McCall MK, Muñoz-Rojas J. Places beyond maps; integrating spatial map analysis and perception studies to unravel landscape change in a Mediterranean mountain area (NE Spain). Appl Geogr. 2014;52:182-90.

81. Campos M, Velázquez A, Verdinelli GB, Skutsch M, Juncà MB, Priego-Santander ángel G. An interdisciplinary approach to depict landscape change drivers: a case study of the Ticuiz agrarian community in Michoacan, Mexico. Appl Geogr. 2012;32:409-19.

82. Vukomanovic J, Orr B. Landscape aesthetics and the scenic drivers of amenity migration in the new west: naturalness, visual scale, and complexity. Land. 2014;3:390-413.

83. Lamarque P, Meyfroidt P, Nettier B, Lavorel S. How ecosystem services knowledge and values influence farmers' decision-making. PLoS One. 2014; doi:10.1371/journal.pone.0107572.

84. Meyfroidt P. Environmental cognitions, land change and socialecological feedbacks: local case studies of forest transition in Vietnam. Hum Ecol. 2013; doi:10.1007/s10745-012-9560-x. Application of the framework from Meyfroidt 2013 (1) for describing the process of landscape change, including the influence of landscape perceptions on management

85. Bieling C. Perceiving and responding to gradual landscape change at the community level: insights from a case study on agricultural abandonment in the black Forest, Germany. Ecol Soc. 2013; doi: 10.5751/ES-05590-180236.

86. Lai P-H, Kreuter UP. Examining the direct and indirect effects of environmental change and place attachment on land management decisions in the hill country of Texas, USA. Landsc Urban Plan. 2012;104:320-8.

87. Vignola R, Koellner T, Scholz RW, McDaniels TL. Decisionmaking by farmers regarding ecosystem services: factors affecting soil conservation efforts in Costa Rica. Land Use Policy. 2010;27: $1132-42$.

88. Hartter J, Goldman A, Southworth J. Responses by households to resource scarcity and human-wildlife conflict: issues of fortress conservation and the surrounding agricultural landscape. J Nat Conserv. 2011;19:79-86.

89. Ariti AT, van Vliet J, Verburg PH. Land-use and land-cover changes in the central Rift Valley of Ethiopia: assessment of perception and adaptation of stakeholders. Appl Geogr. 2015;65:28-37. 
90. de Groot R. Function-analysis and valuation as a tool to assess land use conflicts in planning for sustainable, multi-functional landscapes. Landsc Urban Plan. 2006;75:175-86.

91. Nassauer JI. Landscape as medium and method for synthesis in urban ecological design. Landsc Urban Plan. 2012;106:221-9.

92. Zolkafli A, Liu Y, Brown G. Bridging the knowledge divide between public and experts using PGIS for land use planning in Malaysia. Appl Geogr. 2017;83:107-17.

93. Gobster PH. Perception and use of a metropolitan recreation greenway system for recreation. Landsc Urban Plan. 1995;33: 401-13.

94. Shafer CS, Lee BK, Turner S. A tale of three greenway trails: user perceptions related to quality of life. Landsc Urban Plan. 2000;49: 163-78.

95. de Groot RS, Alkemade R, Braat L, Hein L, Willemen L. Challenges in integrating the concept of ecosystem services and values in landscape planning, management and decision making. Ecol Complex. 2010;7:260-72.

96. Butler A. Dynamics of integrating landscape values in landscape character assessment: the hidden dominance of the objective outsider. Landsc Res. 2016;41:239-52.

97. Bryan BA, Raymond CM, Crossman ND, Macdonald DH. Targeting the management of ecosystem services based on social values: where, what, and how? Landsc Urban Plan. 2010;97:111-22.

98. Rogge E, Nevens F, Gulinck H. Reducing the visual impact of "greenhouse parks" in rural landscapes. Landsc Urban Plan. 2008;87:76-83.

99. Reed P, Brown G. Values suitability analysis: a methodology for identifying and integrating public perceptions of ecosystem values in forest planning. J Environ Plan Manag. 2003;46:643-58.

100. Brown G, Weber D. Public participation GIS: a new method for national park planning. Landsc Urban Plan. 2011;102:1-15.

101. Zhu X, Pfueller S, Whitelaw P, Winter C. Spatial differentiation of landscape values in the Murray river region of Victoria, Australia. Environ Manag. 2010;45:896-911.

102. Brown G, Raymond CM. Methods for identifying land use conflict potential using participatory mapping. Landsc Urban Plan. 2014;122:196-208

103. Karimi A, Brown G, Hockings M. Methods and participatory approaches for identifying social-ecological hotspots. Appl Geogr. 2015;63:9-20.

104. Bagstad KJ, Reed JM, Semmens DJ, Sherrouse BC, Troy A. Linking biophysical models and public preferences for ecosystem service assessments: a case study for the southern Rocky Mountains. Reg Environ Chang. 2015;16:2005-18.

105. Bagstad KJ, Semmens DJ, Ancona ZH, Sherrouse BC. Evaluating alternative methods for biophysical and cultural ecosystem services hotspot mapping in natural resource planning. Landsc Ecol. 2017;32:77-97.

106. Brown G, Kyttä M. Key issues and research priorities for public participation GIS (PPGIS): a synthesis based on empirical research. Appl Geogr. 2014;46:126-36.

107. Daniel TC, Muhar A, Arnberger A, et al. Contributions of cultural services to the ecosystem services agenda. Proc Natl Acad Sci. 2012;109:8812-9.

108. Verburg PH, Dearing JA, Dyke JG, van der Leeuw S, Seitzinger S, Steffen W, et al. Methods and approaches to modelling the Anthropocene. Glob Environ Chang. 2015; doi:10.1016/j. gloenvcha.2015.08.007.

109. Robinson DT, Brown DG. Evaluating the effects of land-use development policies on ex-urban forest cover: an integrated agentbased GIS approach. Int J Geogr Inf Sci. 2009;23:1211-32.

110. Matthews R. The people and landscape model (PALM): towards full integration of human decision-making and biophysical simulation models. Ecol Model. 2006;194:329-43.
111. Rounsevell MDA, Arneth A. Representing human behaviour and decisional processes in land system models as an integral component of the earth system. Glob Environ Chang. 2011;21:840-3.

112. Rounsevell MDA, Arneth A, Alexander P, et al. Towards decisionbased global land use models for improved understanding of the earth system. Earth Syst Dyn. 2014;5:117-37.

113. Council NR. Advancing land change modeling: opportunities and research requirements. Washington, D.C.: National Academy Press; 2014.

114. Dorning MA, Koch J, Shoemaker DA, Meentemeyer RK. Simulating urbanization scenarios reveals tradeoffs between conservation planning strategies. Landsc Urban Plan. 2015;136:28-39.

115. Tian G, Ma B, Xu X, Liu X, Xu L, Liu X, et al. Simulation of urban expansion and encroachment using cellular automata and multi-agent system model - a case study of Tianjin metropolitan region, China. Ecol Indic. 2016;70:439-50.

116. Claessens L, Schoorl JM, Verburg PH, Geraedts L, Veldkamp A. Modelling interactions and feedback mechanisms between land use change and landscape processes. Agric Ecosyst Environ. 2009; 129:157-70.

117. Lewis JL, Sheppard SRJ. Culture and communication: can landscape visualization improve forest management consultation with indigenous communities? Landsc Urban Plan. 2006;77:291-313.

118. Schroth O, Hayek UW, Lange E, Sheppard SRJ, Willy A. Multiple-case study of landscape visualizations as a tool in transdisciplinary planning workshops. Landsc J. 2011;30:53-71.

119. Dockerty T, Appleton K, Lovett A. Public opinion on energy crops in the landscape: considerations for the expansion of renewable energy from biomass. J Environ Plan Manag. 2012;55:1134-58.

120. Ghadirian P, Bishop ID. Integration of augmented reality and GIS: a new approach to realistic landscape visualisation. Landsc Urban Plan. 2008;86:226-32.

121. Griffon S, Nespoulous A, Cheylan JP, Marty P, Auclair D. Virtual reality for cultural landscape visualization. Virtual Real. 2011;15: 279-94.

122. Zank B, Bagstad KJ, Voigt B, Villa F. Modeling the effects of urban expansion on natural capital stocks and ecosystem service flows: a case study in the Puget sound, Washington, USA. Landsc Urban Plan. 2016;149:31-42.

123. Jacobsen JK. Use of landscape perception methods in tourism studies: a review of photo-based research approaches. Tour Geogr. 2007;9:234-53.

124. Dumyahn SL, Pijanowski BC. Soundscape conservation. Landsc Ecol. 2011;26:1327-44.

125. Smith JW, Pijanowski BC. Human and policy dimensions of soundscape ecology. Glob Environ Chang. 2014;28:63-74.

126. Brown G, Strickland-Munro J, Kobryn H, Moore SA. Mixed methods participatory GIS: an evaluation of the validity of qualitative and quantitative mapping methods. Appl Geogr. 2017;79: 153-66.

127. Gibson CC, Ostrom E, Ahn TK. The concept of scale and the human dimensions of global change: a survey. Ecol Econ. 2000;32:217-39.

128. Opdam P. Incorporating multiple ecological scales into the governance of landscape services. In: Scale-Sensitive Gov. Environ.; 2014. p. 17-37.

129. Surová D, Surový P, de Almeida RN, Pinto-Correia T. Integrating differentiated landscape preferences in a decision support model for the multifunctional management of the Montado. Agrofor Syst. 2011;82:225-37.

130. Brown G, Kelly M, Whitall D. Which "public"? Sampling effects in public participation GIS (PPGIS) and volunteered geographic information (VGI) systems for public lands management. J Environ Plan Manag. 2014;57:190-214. 
131. Landuyt D, Van der Biest K, Broekx S, Staes J, Meire P, Goethals PLM. A GIS plug-in for Bayesian belief networks: towards a transparent software framework to assess and visualise uncertainties in ecosystem service mapping. Environ Model Softw. 2015;71:30-8.

132. Grêt-Regamey A, Brunner SH, Altwegg J, Bebi P. Facing uncertainty in ecosystem services-based resource management. J Environ Manag. 2013;127:S145-54.

133. Lechner AM, Raymond CM, Adams VM, Polyakov M, Gordon A, Rhodes JR, et al. Characterizing spatial uncertainty when integrating social data in conservation planning. Conserv Biol. 2014;28:1497-511.

134. Hamel P, Bryant BP. Uncertainty assessment in ecosystem services analyses: common challenges and practical responses. Glob Environ Chang. 2015;24:1-33.

135. Bonney R, Shirk JL, Phillips TB, Wiggins A, Ballard HL, MillerRushing AJ, et al. Next steps for citizen science. Science. 2014;343(80):1436-7.
136. Metaxas P, Mustafaraj E. Sifting the sand on the river bank: social media as a source for research data. Inform Technol. 2014;56:230-9.

137. Xu G, Zhu X, Fu D, Dong J, Xiao X. Automatic land cover classification of geo-tagged field photos by deep learning. Environ Model Softw. 2017;91:127-34.

138. Dickinson JL, Shirk J, Bonter D, Bonney R, Crain RL, Martin J, et al. The current state of citizen science as a tool for ecological research and public engagement. Front Ecol Environ. 2012;10: 291-7.

139. Filatova T, Van Der Veen A, Parker DC. Land market interactions between heterogeneous agents in a heterogeneous landscapetracing the macro-scale effects of individual trade-offs between environmental amenities and disamenities. Can J Agric Econ. 2009;57:431-57. 